\title{
Preceptos historiales
}

Cada diez o doce años nos sale un libro, la mayoría de las veces una novela o quizás un libro de poesías, que señala rumbos nuevos en la literatura de la América latina. Recientemente ocurrió uno de estos descubrimientos afortunados, pero no en la literatura sino en el ramo menos común de los estudios históticos, y que nos lleva a la época colonial.

Me refiero a la copia de los Preceptos historiales, obra del historiador guatemalteco del siglo xvir, Francisco Antonio de Fuentes y Guzmán, descubierta por el doctor Heinrich Berlín en 1957 en la Biblioteca Palafoxiana de la ciudad de Puebla en México.*

Estos Preceptos forman una obra singular, porque representan las reflexiones vivas del autor ${ }_{2}$ un historiador dedicado, y no teorías abstractas: Fuentes y Guzmán redactó este manual para of recer sus ideas sobre la historiografía mientras escribía su gran Recordación florida; probablemente fue una defensa de sus aficiones literarias, que sus amigos no veían con buenos ojos. El descubrimiento nos interesa porque refleja la vida intelectual de Centroamérica durante los tiempos coloniales; fue escrito por Ios años después de I689, y aparentemente hacia I694. La edición actual ha sido preparada por el profesor Ernesto Chinchilla Aguilar y editada por el Ministerio de Educación Pública guatemalteco, con un prefacio del poeta Carlos Samayoa Chinchilla.

Fuentes y Guzmán escribió la historia de Guatemala por orden del rey Carlos II. Habla en la página 48 de "La grande utilidad" de la historia, e insiste en la obligación a que la estudien los nobles y reyes; en la página que sigue; dice que es una "delectación" para los reyes, quienes aprenden cómo gobernar al estudiarla. El objeto de esta ciencia es el mis. mo hombre, y la atención del historiador "se dirige a las repúblicas, reinos

* Fuentes y Guzmán, Francisco Antonio de, Preceptos bistoriales (Ministerio de Educación Pública, Guatemala, 1958). 
y comunidades, cuyos cuerpos místicos componen los mismos hombres" (47), un concepto netamente humanista.

El Tratado Primero del libro lleva por subtítulo: "Elogios Prohemia. les de la Historia. Dignidad y Provechos de Ella". La historia queda después de todas las calamidades; su utilidad para los reyes consiste en que así contemplan la consecuencia de las decisiones injustas (38). En la sección sobre la "Origen Preciosa o Venerable Antigüedad de la Historia", explica que "La simple tradición dio el origen a la historia" y que después "fue puliéndose y adornándose" (43). Menciona muchos nombres $y$ estas citas nos of recen una buena idea de las bibliotecas que existían en el reino de Guatemala hacia fines del siglo xvir. Un apéndice que empieza en la página 133 nos da una lista de las obras y autores citados en el libro, entre clásicos, castellanos y modernos. Conoce los nombres de los meses en hebreo (59) y en la página 65, cita a Polibio, aunque en latín y no en su original griego, a pesar de saber este idioma. Conoce asimismo las Sagradas Escrituras.

El rey Alfonso el Sabio, el "ilustrado y beato Raymundo Lulio" (73) y Tomás de Aquino ( I $2 \mathrm{I}$ ) son las figuras medievales que se destacan aquí. Se presenta como una mezcla curiosa de europeo y de americano, el criollo que se iba cuajando durante la colonia: su patriotismo va tanto hacia España como hacia Guatemala. En el fondo prefiere a ésta: "Goathemala, reino dilatado y rico, y que es aparte de los dos de México y Lima", canta líricamente en la Recordación; y cuando habla de la arquitectura, menciona la catedral de Guatemala como ejemplo.

El Tratado Segundo habla de las "Partes Definibles de la Historia". Fuentes y Guzmán tiene una mentalidad analítica: da la etimología de Quezaltenango, diciendo que esta ciudad se llamaba Xelajuh antes de la llegada de los españoles y mexicanos; Goathemala proviene de "Coctemalam", que significa 'palo de leche'; un abquib es un 'divino' indígena. Más tarde dice que se debe deletrear claramente los nombres indios; pero si es difícil comprenderlos, entonces habrá que transcribirlos bien y traducirlos al castellano. Vemos, pues, que nuestro autor es muy guatemalteco.

Después de la "División y la Subdivisión", viene un pasaje sobre el "Objeto" de la historia: "el hombre... en cuanto trata y habla de los públicos negocios y particulares acciones" entiende como "mirarse en las acciones ordenadas, o en la corrupción de costumbres de sus progenitores o antepasados, ha de hacer el estímulo o el pudor que adelanta las virtudes o reprime los vicios de los presentes..." (47-48). El "Fin" de la 
historia "no sólo no es escribir las cuentas para que no se olviden, sino para premio y encomio de los varones ilustres, héroes grandes, cuyos valerosos o prudentes hechos, virtudes claras y obras heroicas sean para ejemplo y dechado a la imitación... Por eso el fin de la historia es la pública utilidad, y su delectación es compañía, propiedad de la grave, suave y elegante narración. . . El oficio de la historia — prosigue en el párrafo siguiente- es manifestar las naturalezas, novedades, costumbres, los tiempos, el orden de los estados, muestras y vestigios de la venerable antigüedad, y la genealogía de nuestros progenitores..." (49).

El historiador no escoge su material, declara en la sección sobre la "Materia", especialmente cuando trabaja con una comisión real: "dándole la materia, es sola la acción del historiador poner de su parte la elocuencia en la locución, y la prudencia en elegir lo notable, abandonando lo menudo y de poca substancia" (5I). No obstante, dice en la página siguiente, que si siente tal inclinación (o más bien, si tiene los recursos financieros y personales necesarios para tal dedicación) puede elegir su propia materia. Una sección sobre la "División de Materia" demuestra cómo ordenarla; "se necesita de la cabeza desembarazada" para que el historiador no caiga "en el vicio de la obscuridad" (53). Nos aconseja poner las cosas "según el orden" y describirlas con claridad. Con la nueva materia, debe el historiador dominar sus pasiones (57). Por el "Cuerpo", quiere decir los datos o hechos.

El Tratado Tercero, que habla "De las Partes Potenciales de la Historia", tiene más interés. Bajo el subtítulo "Orden", recomienda la censura, al decir: "debe el historiador callar toda acción fea y deshonesta... sería más escribir documentos torpes, que historia ejemplar..." (62). En su "Juicio de las Personas", sin embargo, dice que se debe declarar si un juez ha sido malo (64). Bajo la rúbrica anterior, "Las Personas", leemos que el historiador necesita saber los nombres de los personajes que figuran en sus páginas, aunque no es preciso saber hasta el último.

Prosigue con esto en el Tratado Cuarto: "De las Partes Integrantes de la Historia". En la sección sobre la "Descripción", dice: "Debe ser descritas las cosas heroicas y las vituperables, sin que se abandonen unas por aborrecibles, ni se hagan aceptables otras por gratas". Recomienda lo que llamamos hoy día la observación psicológica: "Y para describir las personas, se debe cometer y usar la figura prosopografia; describiendo y haciendo patente su delineamiento" (7I); el historiador debe averiguar "con desvelo los motivos" dice bajo "Juicio" (78).

"La digresión nace y se produce del orden de la propia narración, 
para así poder ampliar y darle más vida. . Mas en el ordenar las digresiones, el historiador procure con gran pulso contenerse dentro de la moderación" porque esto lo recomienda Tucídides (74-5). "Las oraciones deben formarse con grande esmero y arte" $(76)$; son mejores si son cortas, "huyendo de imitar a Tucídides en ocasiones prolijas" sugiere, en un desacuerdo con su maestro griego. Así vemos que Fuentes y Guzmán tenía criterio propio. El historiador debe "no mezclar refranes en lugar de sentencias", usándolos únicamente de vez en cuando, como joyas; una sentencia, o dicho, es sólo "una brevísima oración formada con escasez de palabras" (82). Cita unos ejemplos: "de la verdad nace el odio"; "la vida es dulce, pero es amargo mantenerlo", etc.

El Tratado Quinto trata "Del Estilo y Elegancia de que Debe Usar el Cronista... debe ser el estilo... no sólo elegante, pero alto, limpio, correcto y atentamente trabajado, con diligencia incansable". Fuentes y Guzmán prefiere "un castellano puro y sin latinizar"; en la sección sobre "Elocución del Estilo Historial" que empieza en la página 88, nos aconseja emplear palabras comunes tales como "prado", "bosque", "río", "cuerpo", siempre que no sean vulgares, y las figuras como "llora el dia" - "se ríen los campos" si éstos ayudan al estilo. Debemos servirnos con moderación de las cosas ordinarias (siempre que no sean vulgares), y dejar "las humildes palabras" para la materia jocosa. Los diminutivos prestan un toque ligero a la narración; las palabras pesadas le dan fuerza.

En la "Oración Figurada", explica cómo Minerva representa la Ciencia, y así por el estilo. Discute la cacofonía y otros defectos. Esto le recuerda la "Composición Metafórica" con términos como "hombre de acero" por "varón fuerte", "bramaba el gobernador", el "león de España" por "nuestro rey", el "Volcán de Agua" por "Guatemala" (95-7), etc. Se encuentran algunos ejemplos lamentables o erróneos en la sección llamada "Composición Antonomástica y de Epiteto", donde llama "Lutero, peste del Cristianismo de Inglaterra", lo mismo como califica a los noCatólicos como "gentiles". Habla de las "Composiciones de Palabras Simples, sin Figura", tales como "Tu pensamiento, tus pies, tus manos, tu valor, ¿qué pretendían?"

La sección sobre la "Locación de Palabras" trata del orden de éstas. Aquí discurre sobre la armonía de las palabras y el valor de las vocales y consonantes (IOI); hay varias secciones sobre esta música hablada que llama "Concinidad y Consonancia Sonora de la Oración". Finalmente habla de la "Imitación y Ejemplar de Autores": "Débese imitar a aquellos que se acomodan más al propio genio y natural ley del que imitare... 
Mas, no debe imitar a muchos..."' (105). Uno puede prestar únicamente unas frases, y citándolas al autor; aconscja que se imite más bien el estilo, y en esto prefiere a Salustio, Livio y César entre los romanos; los cronistas españoles como Lucas de Tuy, el arzobispo, Raimundo de Toledo, el rey Alfonso, y Mariana; o americanos como el Inca Garcilaso y Solís (I06-7). Hernán Cortés era un personaje muy presente en la mente de este guatemalteco vástago de conquistadores ( I I6).

En la sección final sobre el "Orden en Distribuir lo que se Escribe y de el Titular las Obras", menciona su Recordación florida; nos dice que escogió este nombre distintivo porque quería recordar "las acciones gloriosas, políticas y militares ejercitadas por nuestros mayores; unas ya referidas por otros autores, aunque defectuosamente; $y$, otros, que han estado en el secreto de los archivos privados" (I08). Únicamente dos siglos y medio más tarde, se publicó su propia historia, como pasó con muchas obras coloniales; la primera parte de su gran Récordación florida apareció en los años I882-3; y el testo en 1932 bajo el patrocinio de la Sociedad de Geografía e Historia de Guatemala. Falta una tercera parte, pero quizás se trate de estos Preceptos bistoriales recientemente descubiertos. Desgraciadamente su misma Recordación iba a encontrar este olvido durante dos siglos, y sus Preceptos casi otro siglo más, triste comentario sobre el alcance de la prensa americana en aquella época.

El Tratado Sexto lleva por subtítulo: "Estilo y Orden que se ha de Guardar en Escribir las Vidas de los Reyes y de los Varones Ilustres". Se demuestra crédulo con las águilas al nacimiento de Alejandro Magno o la música de ángeles en la muerte de San Fernando (II3). Dedica una sección entera "De Cómo de Estos Nombres Fortuna, Hado, Destino y Suerte Debe el Historiador Usar, y no de Otros", para demostrar cómo cambia la fortuna humana.

Por fin discurre sobre "Cuan Propio Sea de los Hombres y Personas Ilustres el Escribir Historia": insiste en que es ocupación sana y nos confiesa que tuvo que dejar de escribir su propia historia de Guatemala porque sus amigos no querían que la redactara por ser "cosa indigna". Cuando ofrece la historiografía como una noble vocación y da una lista de historiadores destacados, desde el rey David hasta su propio siglo, oímos una nota personal, como si quisiese defender sus gustos. Si un hombre activo y serio como el capitán y regidor Fuentes y Guzmán no podía dedicarse de lleno a estas labores, comprendemos por qué tantas historias americanas han salido de los conventos. Otro elemento personal es la observación de que es mejor publicar durante la vida del autor, que des- 
pués de su muerte (I24); parece una alusión a la suerte que sufrió la Verdadera y notable bistoria de su tatarabuelo.

En el apéndice de este nuevo tomo, leemos su 'parecer sobre la crónica de Vázquez, (I29-132) con fecha del año r694; y otro apéndice, fruto de las labores del profesor Chinchilla con la lista ya mencionada de los libros que el cronista había leído. Este apéndice es valiosísimo como comentario sobre los conocimientos históricos en Centroamérica hace tres siglos.

En suma, este nuevo libro debe llevar a una revaloración de las obras de Fuentes y Guzmán, para colocarlo debidamente entre los historiadores más prestigiados de su época, no sólo en América sino también en Europa. Aquí tenemos una de las obras más importantes que ha publicado aquella nueva escuela que se desarrolla alrededor de la figura incansable de don Joaquín Pardo, director del Archivo Nacional de Guatemala. Yo estaba leyendo la Recordación florida en el momento de la aparición de los Preceptos historiales, y este suceso me hizo leer la crónica con interés aumentado; mis impresiones renovadas llevarian a unas observaciones demasiado extensas para este comentario. Basta con decir que Samayoa Chinchilla dice en la página I 6 de esta edición que Fuentes y Guzmán escribió con un estilo "excesivamente recargado", con lo que no estoy de acuerdo: nuestro cronista describe maravillosamente la vida centroamericana de su época, y sin el obscurantismo tan barato que se refleja en la novela Mostaza, por ejemplo. Así se debe felicitar sinceramente al equipo que sacó esta pequeña obra maestra a la luz del día en un plazo tan corto y después de un olvido tan largo.

Thomas B. Inving,

Universidad de Minnesota. 